\title{
Aged Mice Exhibit Severe Exacerbations of Dry Eye Disease with an Amplified Memory Th17 Cell Response
}

William Foulsham, ${ }^{\star \dagger}$ Sharad K. Mittal, ${ }^{*}$ Yukako Taketani, ${ }^{*}$ Yihe Chen, ${ }^{*}$ Takeshi Nakao, ${ }^{*}$ Sunil K. Chauhan, ${ }^{*}$ and Reza Dana*

From the Schepens Eye Research Institute, ${ }^{*}$ Harvard Medical School, Boston, Massachusetts; and the Institute of Ophthalmology, ${ }^{\dagger}$ University College London, London, United Kingdom

Accepted for publication March 26, 2020.

Address correspondence to Reza Dana, M.D., M.Sc., M.P.H., Schepens Eye Research Institute, 20 Staniford St., Boston, MA 02114. E-mail: reza dana@meei.harvard.edu.

\begin{abstract}
The prevalence as well as the severity of dry eye disease increase with age. Memory T helper 17 (Th17) cells $\left(C D 4^{+} \mathrm{IL}-17 \mathrm{~A}^{+} \mathrm{CD} 44^{+}\right)$drive the chronic and relapsing course of dry eye disease. Here, we investigated the contribution of memory Th17 cells to age-related dry eye disease, and evaluated memory Th17 cell depletion with anti-IL-15 antibody as a strategy to abrogate the severe exacerbations of dry eye disease observed in aged mice. After initial exposure to desiccating stress, aged mice maintained higher frequencies of memory Th17 cells in the draining lymph nodes relative to young mice. Upon secondary exposure to desiccating stress, aged mice developed more severe corneal epitheliopathy than young mice, which is associated with increased local frequencies of Th17 cells (CD4 ${ }^{+} \mathrm{IL}-17 \mathrm{~A}^{+}$). Treatment with anti-IL-15 antibody decreased the enlarged memory Th17 pool in aged mice to frequencies comparable with young mice. Furthermore, anti-IL-15-treated mice showed significantly reduced conjunctival infiltration of Th17 cells and lower corneal fluorescein staining scores compared with salinetreated control mice. Our data suggest that age-related increases in the memory Th17 compartment predispose aged mice toward the development of severe corneal epithelial disease after exposure to a dry environment. Selectively targeting memory Th17 cells may be a viable therapeutic approach in the treatment of age-related dry eye disease. (Am J Pathol 2020, 190: 1474-1482; https://doi.org/10.1016/ j.ajpath.2020.03.016)
\end{abstract}

Aging results in a general decrease in immune function, observed clinically as increased vulnerability to infection ${ }^{1}$ and impaired responses to vaccination. ${ }^{2}$ However, paradoxically, advanced age is also a risk factor for autoimmunity. ${ }^{3}$ A hallmark of adaptive immunity, immunologic memory permits antigen-experienced lymphocytes to respond rapidly and robustly to repeat exposures to the same antigen. ${ }^{4}$ Through cognition of self-antigen, immunologic memory also contributes toward chronic inflammation in autoimmunity. ${ }^{5-9}$ Identifying the role of memory lymphocytes in age-related autoimmune diseases represents a key step in understanding the immunopathogenesis of these chronic inflammatory disorders.

Dry eye disease (DED) is an extremely common chronic condition that significantly impairs patient quality of life. $^{10-12}$ DED is a multifactorial disease of the ocular surface characterized by ocular surface inflammation, loss of tear film homeostasis, and neurosensory dysfunction. ${ }^{13}$ The prevalence of DED increases with age, with a recently published retrospective study of a large US population estimating a prevalence of $0.2 \%$ for patients age 2 to 17 years, increasing to $11.7 \%$ for patients older than age $50 .^{14}$ The disruption of ocular surface homeostasis is recognized as the trigger of DED immunopathogenesis. ${ }^{15,16} \mathrm{~A}$ proinflammatory milieu at the ocular surface induces the maturation of antigen-presenting cells, which migrate via afferent lymphatics to the draining lymph nodes. ${ }^{17-21}$ Here, antigenpresenting cells induce the differentiation of effector helper $\mathrm{T}$ cells (Th) that migrate through the efferent blood vessels to the ocular surface, where they release proinflammatory

Supported in part by NIH grant EY020889 (R.D.) and NIH Core grant P30EY003790 (Schepens Eye Research Institute).

Disclosures: None declared. 
factors. ${ }^{17-19,22}$ Thus, the immunopathogenesis of DED can be understood as a self-perpetuating cycle, whereby a proinflammatory microenvironment engenders further infiltration of pathogenic immune cells and increases damage to the ocular surface. ${ }^{23,24}$

Th17 cells have emerged as key effector immune cells in DED, ${ }^{25-27}$ mirroring their immunopathogenic role in autoimmune conditions such as uveitis/scleritis, ${ }^{28}$ rheumatoid arthritis, ${ }^{29}$ inflammatory bowel disease, ${ }^{30}$ and multiple sclerosis. ${ }^{31}$ Experimental desiccating stress-induced DED is a well-recognized preclinical model of ocular surface autoimmunity. ${ }^{25,32}$ Memory Th17 cells $\left(\mathrm{CD} 4{ }^{+} \mathrm{CD} 44^{\mathrm{hi}} \mathrm{IL}-17 \mathrm{~A}^{+}\right)$are critical mediators of DED chronicity, and are responsible for the heightened disease severity observed when mice are rechallenged with desiccating stress. ${ }^{33}$ In the experimental autoimmune encephalitis model, memory Th17 cells also have been implicated in promoting earlier onset and increased severity of clinical disease after rechallenge. ${ }^{9}$ However, the contribution of the memory Th17 cell population to age-associated ocular surface autoimmunity is not known.

In the present study, we investigated the role of memory Th17 cells in DED pathogenesis in aged mice. Specifically, DED severity was evaluated in young (6- to 8-week-old) versus aged (12- to 14-month-old) mice during primary and secondary challenges. We quantified memory Th17 populations in young versus aged mice after exposure to desiccating stress, and evaluated memory Th17 cell depletion as a strategy to treat severe DED exacerbations in aged mice.

\section{Materials and Methods}

\section{Animals}

Six- to 8-week-old (young) and 12- to 14-month-old (aged) female C57BL/6 mice from Charles River Laboratories (Wilmington, MA) were used in these experiments. Animals were housed in the Schepens Eye Research Institute animal vivarium. Animals were treated according to The Association for Research in Vision and Ophthalmology's Statement for the Use of Animals in Ophthalmic and Vision Research. Experiments were approved by the Schepens Eye Research Institute Animal Care and Use Committee.

\section{Dry Eye Model}

DED was induced as described previously. ${ }^{33-35}$ In brief, mice were housed for 14 days in a controlled environment
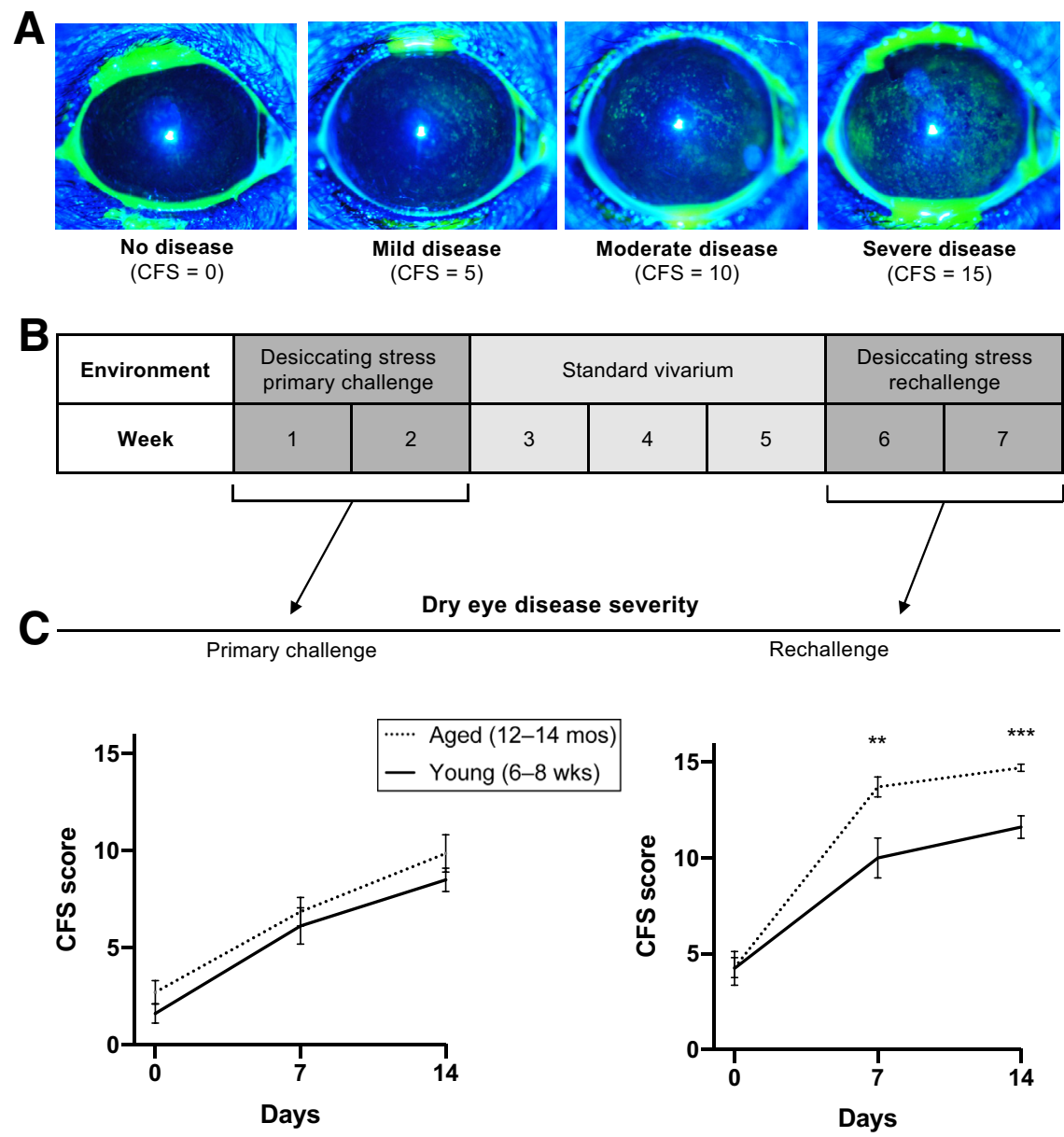

Figure 1 Aged mice develop more severe dry eye disease (DED) compared with young mice on secondary, but not primary, exposure to desiccating stress. A: DED was evaluated by corneal fluorescein staining (CFS), with representative disease severities. DED was induced by exposing mice to desiccating stress for 2 weeks (ie, primary challenge). After this, mice were housed in a standard vivarium for 3 weeks. B: Subsequently, mice were rechallenged for a further 2-week period (ie, secondary challenge). C: No difference in CFS score is detected between young and aged mice on primary exposure to desiccating stress (left panel). However, aged mice show significantly greater CFS scores relative to young mice at both 7 days and 14 days after rechallenge (right panel). Data are expressed as means \pm SEM and are representative of two independent experiments. $n=7$ or 8 animals in each group (left eye only). ${ }^{* *} P<0.01,{ }^{* * *} P<0.001$ versus young. 
chamber with continuous airflow of $15 \mathrm{~L} / \mathrm{min}$ and relative humidity maintained at less than $20 \%$. Naive control mice were housed in the standard vivarium. Corneal epitheliopathy was assessed by administering $1 \mu \mathrm{L}$ of $1 \%$ fluorescein (Sigma-Aldrich Corp., St. Louis, MO) to the lateral conjunctival sac using a micropipette. After 3 minutes, punctate staining was evaluated using a slit-lamp biomicroscope under cobalt blue light, and the left eye of each mouse was scored according to the National Eye Institute grading scale. ${ }^{36}$ The role of IL-15 in promoting the homeostatic proliferation of memory $\mathrm{CD}^{+} \mathrm{T}$ cells is well recognized, however, IL-15 signaling also has been shown to have a prominent nonredundant role in the survival and proliferation of memory $\mathrm{CD}^{+}{ }^{+}$ cells. ${ }^{35,37-39}$ In this study, in vivo blockade with anti-IL-15 monoclonal antibody was used as a strategy to deplete the memory Th17 pool. Specifically, mice were administered either anti-IL-15 monoclonal antibody $(25 \mu \mathrm{g}$ in $100 \mu \mathrm{L}$ sterile saline, Clone AIO.3; eBioscience, San Diego, CA) or control (100 $\mu \mathrm{L}$ sterile saline) once daily via i.p. injection for 7 days.

\section{Flow Cytometry}

Submandibular and draining lymph nodes were collected using jewelers forceps (Katena Products, Inc., Denville, NJ). Conjunctivae were harvested using jewelers forceps and Vannas scissors (Storz; Bausch \& Lomb, Rochester, NY), before being digested in RPMI media (Lonza, Walkersville, MD) containing $2 \mathrm{mg} / \mathrm{mL}$ collagenase type IV (SigmaAldrich Corp.) and $2 \mathrm{mg} / \mathrm{mL}$ DNase I (Roche, Basel, Switzerland) for a duration of 45 minutes at a temperature of $37^{\circ} \mathrm{C}$, as described previously. ${ }^{40,41}$ Subsequently, cells were passed through a $70-\mu \mathrm{m}$ cell strainer (Falcon; Corning Life Sciences, Corning, NY). Single-cell suspensions were stained with the following fluorochrome-conjugated monoclonal antibodies: fluorescein isothiocyanate-conjugated anti-CD4 and peridinin-chlorophyll protein complex cyanine 5.5-conjugated anti-CD44 (BioLegend, San Diego, CA). For intracellular IL-17 staining, cells were stimulated with $50 \mathrm{ng} / \mathrm{mL}$ phorbol 12-myristate 13-acetate and $500 \mathrm{ng} /$ $\mathrm{mL}$ ionomycin (Sigma-Aldrich Corp.) for 6 hours at $37^{\circ} \mathrm{C}$ and $5 \% \mathrm{CO}_{2}$ in the presence of GolgiStop $(4 \mu \mathrm{L}$ per $6-\mathrm{mL}$ cell culture; BD Biosciences, San Jose, CA) to inhibit cytokine secretion. After this, cells were stained for phycoerythrin-conjugated anti-IL-17A (BioLegend). Control samples were stained with isotype-matched control antibodies. Stained cells were analyzed using a LSR II flow cytometer (BD Biosciences) and Summit software version 4.3 (Dako Colorado, Inc., Fort Collins, CO). Gating strategies for selecting $\mathrm{CD} 4^{+}$cells are shown in Supplemental Figure S1.

\section{Statistical Analysis}

Unpaired, two-tailed, $t$-tests and 2-way analysis of variance tests were used as appropriate to determine significance, which was set at $P<0.05$. Data are presented as means \pm SEM. Sample sizes were based on previous experimental studies of DED. ${ }^{33,35,42}$

\section{Results}

Aged Mice Develop Severe Dry Eye Disease Compared with Young Mice on Secondary, but Not Primary, Exposure to Desiccating Stress

To evaluate corneal epitheliopathy after exposure to desiccating stress, corneal fluorescein staining was used, with representative images of different disease severities shown in Figure 1A. To examine the difference in clinical disease between young and aged mice on exposure to a dry environment, mice were housed in the controlled environment chamber for a period of 14 days, as previously described. ${ }^{34,42,43}$ Mice subsequently were returned to a standard vivarium for 21 days, before undergoing rechallenge with a further 14 days of desiccating stress (Figure 1B). No difference in corneal fluorescein staining score between young and aged mice was observed at baseline (young, 1.6; aged, 2.7), after 7 days of desiccation (young, 6.1; aged, 6.9), or after 14 days of desiccation (young, 8.5; aged, 9.9) (Figure 1C). However, upon rechallenge, substantially higher scores of corneal epitheliopathy were observed in aged mice compared with young mice ( 7 days: young, 10.0; aged, 13.7, $P=0.009 ; 14$ days: young, 11.6; aged, 14.7, $P<0.001$ ) (Figure 1C).

\section{Aged Mice Exhibit an Enhanced Th17 Immune} Response Compared with Young Mice after Desiccating Stress Rechallenge

Th17 cells have been identified as critical effector cells promoting inflammation in DED. ${ }^{25-27}$ In view of our data showing severe corneal epitheliopathy in aged compared with young mice after rechallenge, we next sought to determine the frequencies of Th17 cells in the respective groups. Aged rechallenged mice were observed to have substantially higher lymph node Th17 frequencies compared with aged naive mice $(4.2 \% \pm 0.3 \%$ versus $1.5 \% \pm 0.3 \%$, respectively; $P=0.004$ ) (Figure 2A). Young rechallenged mice also had a tendency for higher Th17 frequencies in the draining lymph nodes relative to naive mice $(1.4 \% \pm 0.5 \%$ versus $0.7 \% \pm 0.3 \%$, respectively; $P=0.248)$. Notably, however, aged mice showed a 3.9fold greater increase in lymph node Th17 frequencies relative to young mice $(2.7 \%$ versus $0.7 \%$, respectively). A twoway analysis of variance was conducted on the influence of age and desiccating stress rechallenge on the corneal fluorescein staining score. All effects were statistically significant at the 0.05 significance level. The main effect for age yielded an $\mathrm{F}$ ratio of $26.5(P<0.001)$, indicating a significant difference between young and aged mice. The main effect for desiccating stress rechallenge yielded an F ratio of 
$9.7(P<0.001)$, showing a significant difference between naive and rechallenged mice. Finally, the interaction effect was significant $(P=0.022)$.

After rechallenge, Th17 frequencies in the conjunctivae of young mice were observed to increase to
$6.6 \% \pm 1.1 \%$ relative to $2.6 \% \pm 0.6 \%$ in naive mice $(P=0.011)$ (Figure 2B). Analysis of the conjunctivae of aged mice showed a 2.2-fold greater increase in Th17 infiltration (aged, 8.9\%; young, $4.0 \%$ ), with frequencies of $11.3 \% \pm 1.2 \%$ detected in aged mice after rechallenge

Gated on $\mathrm{CD} 4^{+}$cells
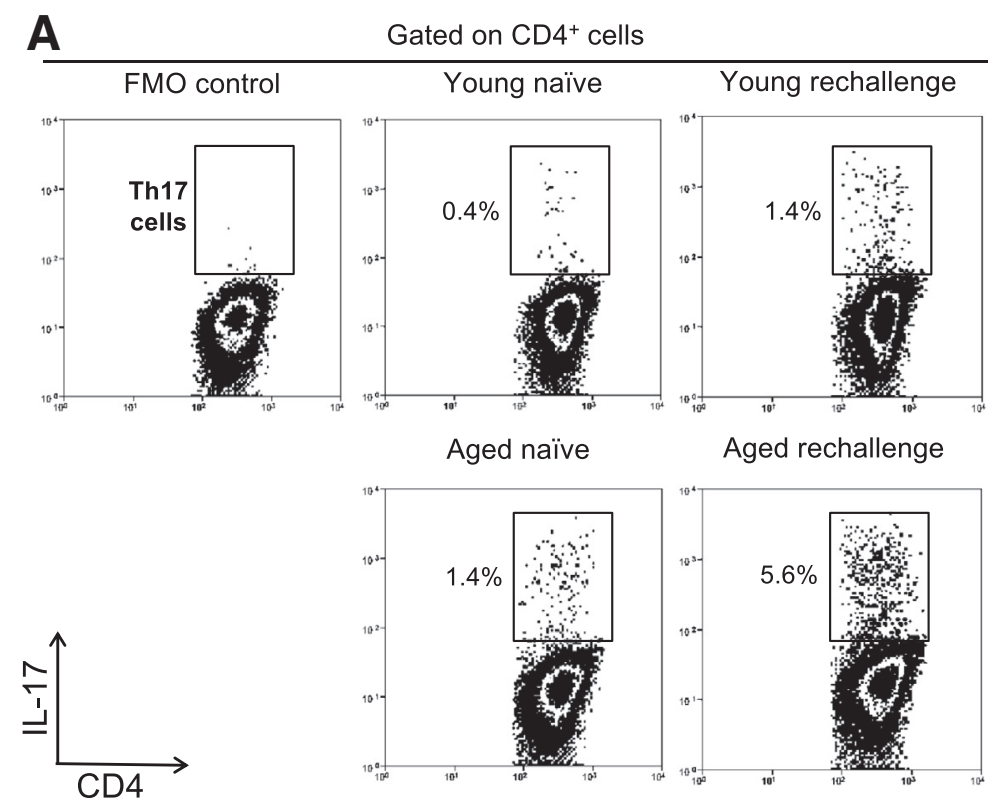

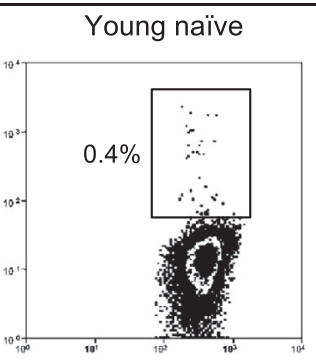

Aged naïve

Young rechallenge

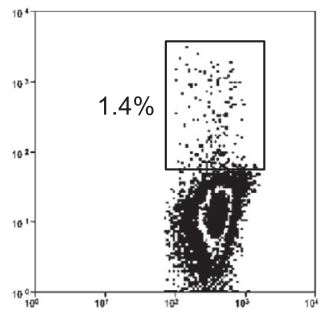

Aged rechallenge
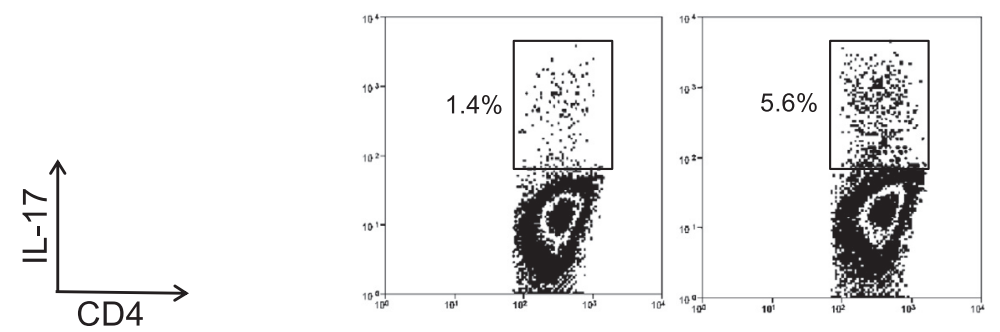

B

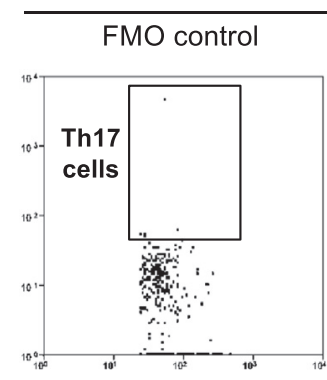

Gated on CD4+ cells
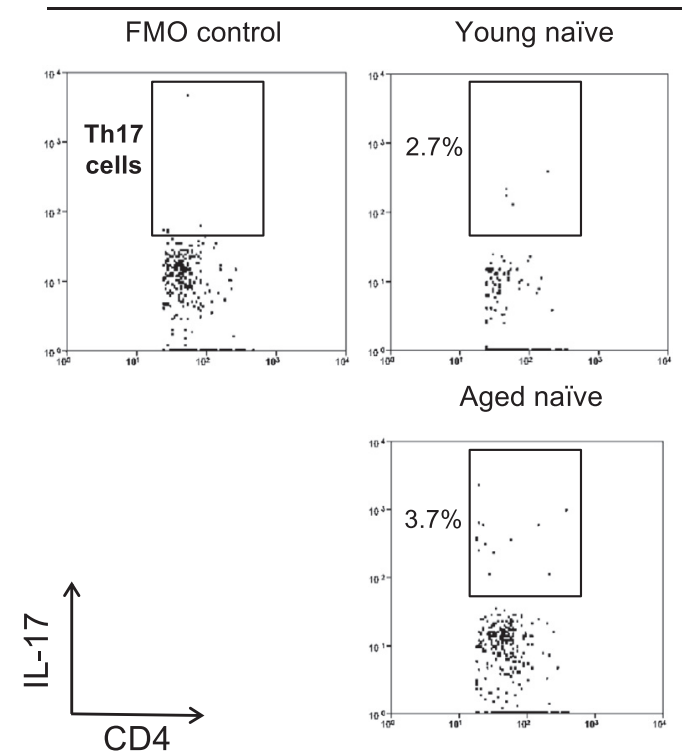

Figure 2 Aged mice show an enhanced helper T (Th)17 cell immune response compared with young mice after secondary challenge. Mice were sacrificed after 2 weeks of desiccating stress rechallenge. Draining lymph nodes and conjunctivae were harvested, single-cell suspensions were prepared, and flow cytometry was performed. A: Representative flow cytometry dot plots (left panel) and bar chart (right panel) showing frequencies of CD $4^{+}$IL-17A ${ }^{+}$Th17 cells in the draining lymph nodes (gated on $\mathrm{CD}^{+}$cells). Data are representative of two independent experiments. B: Representative flow cytometry dot plots (left panel) and bar chart (right panel) showing frequencies of $\mathrm{CD}^{+} \mathrm{IL}-17 \mathrm{~A}^{+}$Th17 cells in the conjunctivae (gated on $\mathrm{CD} 4^{+}$cells). Data presented on bar graphs are combined results from two independent experiments. Two-way analysis of variance show a significant interaction effect with $P<0.05$ in both $\mathbf{A}$ and $\mathbf{B}$. Data are expressed as means \pm SEM. $n=3$ to 4 animals $(\mathbf{A}) ; n=4$ to 5 conjunctival samples, with each sample being pooled from 3 to 4 conjunctivae (B). ${ }^{*} P<0.05,{ }^{* *} P<0.01$, and ${ }^{* * *} P<0.001$. DLN, draining lymph nodes; FM0, fluorescence minus one. 
A

\begin{tabular}{|c|c|c|c|c|c|c|}
\hline Environment & \multicolumn{2}{|c|}{$\begin{array}{l}\text { Desiccating stress } \\
\text { primary challenge }\end{array}$} & \multicolumn{2}{|c|}{ Standard vivarium } & \multicolumn{2}{|c|}{$\begin{array}{l}\text { Desiccating stress } \\
\text { rechallenge }\end{array}$} \\
\hline Week & 1 & 2 & 4 & 5 & 6 & 7 \\
\hline Naïve & \multicolumn{3}{|c|}{ Tissue analysis before rechallenge } & \multicolumn{3}{|c|}{ Tissue analysis after rechallenge } \\
\hline
\end{tabular}

Week 3 only: Treatment with anti-lL-15 $(25 \mu \mathrm{g}) \mathrm{mAb}$ or sterile saline once daily via IP injection

B

Gated on $\mathrm{CD} 4^{+}$
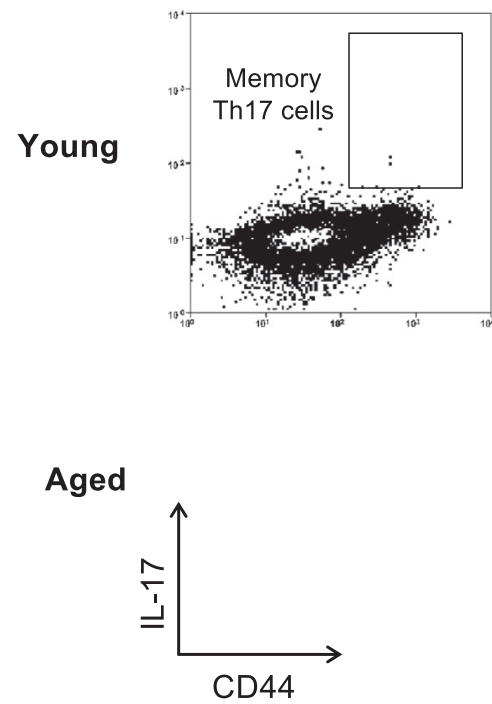

\section{C}

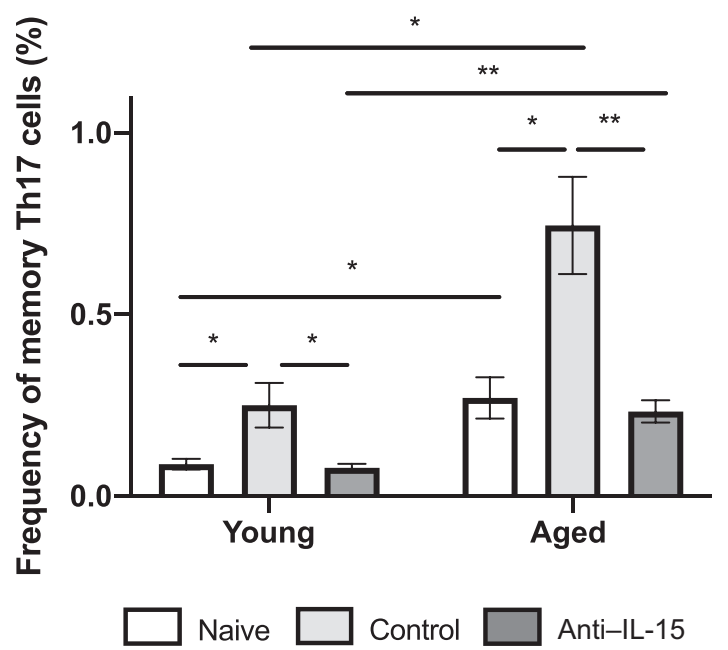

Figure 3 Anti-IL-15 monoclonal antibody (mAb) diminishes the expanded memory helper $\mathrm{T}(\mathrm{Th}) 17$ cell population observed in aged mice after primary challenge. After primary challenge of 2 weeks of desiccation, mice were transferred to a standard vivarium. A: Mice received daily i.p. injection of either anti-IL-15 mAb or saline for 7 days. After an additional 2 weeks in room air, a number of mice were sacrificed for tissue analysis before rechallenge. The remaining mice were rechallenged for 2 weeks before being sacrificed for tissue analysis after rechallenge. Single-cell suspensions were prepared and flow cytometry was performed. B and C: Representative dot plots (B) and bar chart (C) showing frequencies of $\mathrm{CD} 4^{+} \mathrm{CD} 44^{+} \mathrm{IL}-17 \mathrm{~A}^{+}$memory Th17 cells before rechallenge in draining lymph nodes of indicated groups (gated on $\mathrm{CD}^{+}$cells). Data are representative of two independent experiments, and each group consisted of four animals. Data are expressed as means \pm SEM. ${ }^{*} P<0.05$, ${ }^{*} P<0.01$. FM0, fluorescence minus one; $\mathrm{N}$, the absolute number of gated events. and $2.4 \% \pm 0.4 \%$ in naive mice $(P<0.001)$. A two-way analysis of variance was performed, with all effects statistically significant at the 0.05 significance level. The main effect for age showed an $\mathrm{F}$ ratio of $7.6(P=0.014)$, showing a significant difference between young and aged mice. The main effect for desiccating stress rechallenge yielded an $\mathrm{F}$ ratio of $43.8(P<0.001)$, showing a significant difference between naive and rechallenged mice. The interaction effect also was significant $(P=0.035)$. 

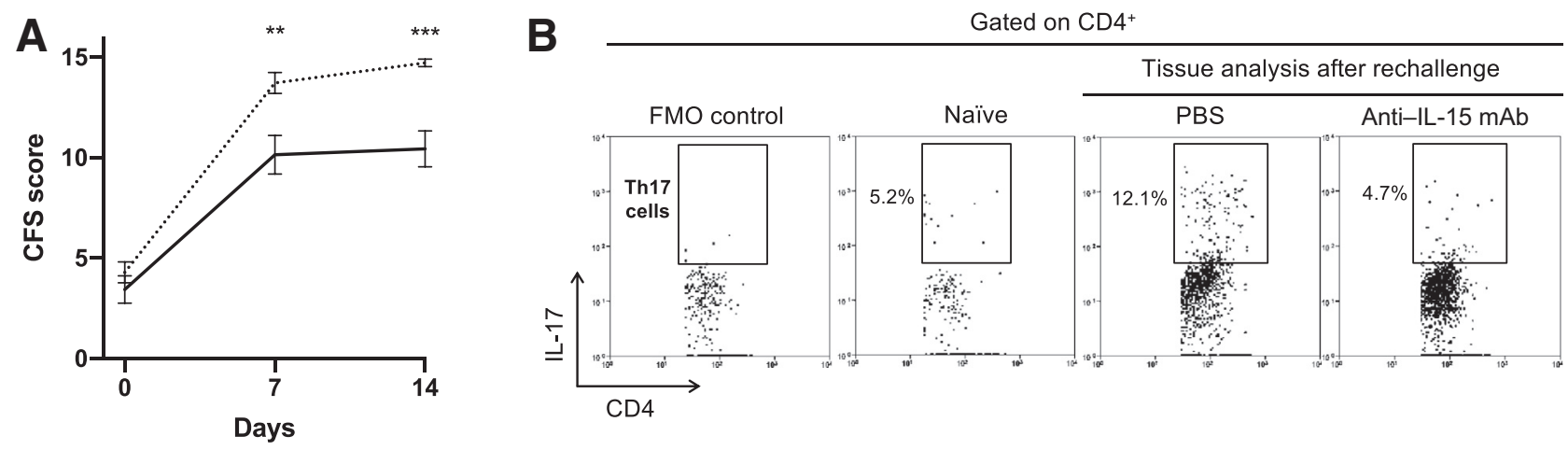

…. Aged control - Aged Anti-IL-15

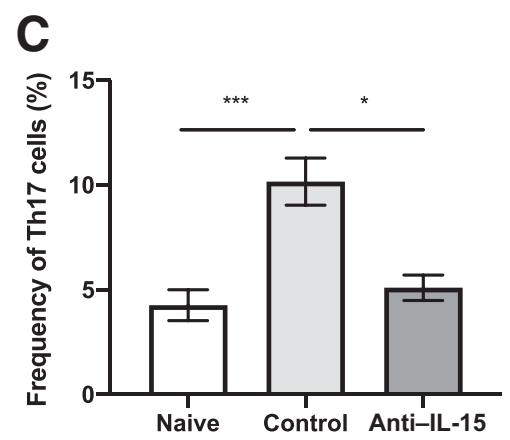

\begin{abstract}
Figure 4 Depletion of the memory helper T (Th)17 cell population abrogates the severe dry eye exacerbations observed in aged mice. After primary exposure to desiccating stress, and administration of anti-IL-15 monoclonal antibody (mAb) or sterile saline (as detailed in Figure $3 \mathrm{~A}$ ), mice were re-exposed to desiccating stress. A: Corneal fluorescein staining (CFS) performed at day 7 and day 14 shows significantly reduced corneal epitheliopathy in aged mice treated with anti-IL-15 mAb compared with saline-treated aged mice ( 7 animals/group; left eye only). After 2 weeks of secondary exposure to desiccating stress, mice were sacrificed. Conjunctivae were harvested, single-cell suspensions were prepared, and flow cytometry was performed. B and C: Representative dot plots (B) and bar chart (C) showing frequencies of $\mathrm{CD}^{+}{ }^{+} \mathrm{IL}-17 \mathrm{~A}^{+}$Th17 cells after rechallenge in conjunctivae of indicated groups (gated on $\mathrm{CD}^{+}$ cells). Data presented are representative of two independent experiments. Data are expressed as means \pm SEM. $n=3$ conjunctival samples per group, with each sample being pooled from four conjunctivae. ${ }^{*} P<0.05,{ }^{* *} P<0.01$, and ${ }^{* * *} P<0.001$. FM0, fluorescence minus one; PBS, phosphate-buffered saline.
\end{abstract}

\section{The Amplified Memory Th17 Cell Population in Aged Mice after Exposure to Desiccating Stress Is Depleted by Systemic Treatment with Anti-IL-15 Monoclonal Antibody}

Memory Th17 cells $\left(\mathrm{CD} 4{ }^{+} \mathrm{CD} 44^{\text {high }} \mathrm{IL}-17^{+}\right)$are critical mediators of the low-grade inflammation observed in chronic DED. ${ }^{33,35}$ To delineate the contribution of memory Th17 cells to the severe exacerbations of DED observed in aged mice, an experiment was designed in which young and aged mice would be treated systemically with anti-IL-15 monoclonal antibody (mAb) after primary challenge with desiccating stress to reduce the memory Th17 population. After 2 weeks in the controlled environment chamber, mice were returned to a standard vivarium for 3 weeks (Figure 3A). During the first of these 3 weeks in the standard vivarium, mice received daily i.p. injections with anti-IL-15 mAb. After these 3 weeks, mice were returned to the controlled environment for a 2-week rechallenge. Mice were sacrificed and their tissues were harvested for immune analysis at two time points: either before rechallenge or after rechallenge. Tissue analysis before rechallenge showed a significant increase in memory Th17 frequencies in both young and aged saline-treated animals that had been exposed previously to desiccating stress relative to naive mice ( $P=0.042$ and $P=0.017$, respectively) (Figure 3, B and C). However, the increase in memory Th17 frequencies in aged mice was substantially greater (approximately threefold) compared with young mice. Treatment with anti-IL-15 abrogated the increase in memory Th17 cells in both young and aged mice $(P=0.032$ and $P=0.010$, respectively) (Figure 3, B and C). A two-way analysis of variance was performed, with all effects statistically significant at the 0.05 significance level. The main effect for age showed an $\mathrm{F}$ ratio of $26.4(P<0.001)$, showing a significant difference between young and aged mice. The main effect for desiccating stress rechallenge yielded an $\mathrm{F}$ ratio of $16.7(P<0.001)$, showing a significant difference between naive rechallenged and anti-IL-15-treated mice. Finally, the interaction effect was significant $(P=0.034)$.

\section{Depletion of the Memory Th17 Cell Population Abrogates the Severe Dry Eye Exacerbations Observed in Aged Mice}

Having observed the reduction in memory Th17 cell frequencies in aged animals resulting from treatment with anti-IL-15 mAb, we sought to determine the effect of memory Th17 cell depletion on DED severity. Mice were exposed to desiccating stress and treatment with anti-IL-15 $\mathrm{mAb}$ as shown in Figure 3A. Evaluation of corneal fluorescein staining scores showed that treatment with anti-IL- 
$15 \mathrm{mAb}$ resulted in a significant reduction in DED severity in aged mice at day $7(26 \% ; P=0.007)$ and at day 14 $(29 \% ; P<0.001)$ after rechallenge (Figure 4A). Mice were sacrificed at 2 weeks after rechallenge, and flow cytometric analysis of single-cell suspensions derived from conjunctivae showed decreased effector Th17 cell infiltration in the anti-IL-15 mAb-treated mice relative to the saline control animals $(5.1 \%$ compared with $10.1 \%$, respectively; $P=0.016$ ) (Figure 4, B and C).

\section{Discussion}

The aged immune system is susceptible to autoimmunity, and many autoimmune conditions preferentially occur later in life. ${ }^{3}$ Despite extensive investigations into the role of effector Th17 cells in autoimmunity, little is known about the contribution of memory Th17 cells to age-related autoimmune conditions. In this study, a murine model of ocular surface autoimmunity was used to show the following: i) aged mice develop more severe exacerbations of DED relative to young mice; ii) after primary exposure to desiccating stress, aged mice maintain an amplified memory Th17 pool; and iii) depletion of the memory Th17 population with anti-IL-15 mAb abrogates both the increased clinical disease and up-regulated tissue infiltration of effector Th17 cells observed in aged mice.

The immune system undergoes a wide variety of changes during aging, and these phenomena collectively are termed immunosenescence. ${ }^{44}$ It is important to note that these changes are not necessarily unidirectional; indeed, some components of the immune system may show improved efficiency in aging. ${ }^{45}$ However, in aggregate, these agerelated changes result in a state of chronic, sterile, lowgrade inflammation called inflamm-aging. ${ }^{46}$ This state of inflamm-aging predisposes the elderly to overt immunemediated disease. ${ }^{47}$ Analysis of age-related changes to human tear composition lends support to the concept of inflamm-aging at the ocular surface because elderly subjects have been shown to have higher levels of inflammatory mediators and tissue remodeling factors in their tears relative to young subjects. ${ }^{48}$ Other changes that occur to the ocular surface environment during aging include decreased goblet cell density ${ }^{49}$ and decreased tear production, ${ }^{50}$ with atrophy and lymphocytic infiltration of the lacrimal gland. ${ }^{51,52}$

In our study, a desiccating stress murine model of DED was used, which recapitulates key aspects of human DED including increased levels of Th17-associated cytokines, corneal barrier dysfunction, secretion of proinflammatory factors by corneal and conjunctival epithelium, and goblet cell loss. ${ }^{21,25,26,53,54}$ No difference was observed in the increase in corneal fluorescein staining score between aged and young mice upon initial exposure to desiccating stress, but on secondary exposure aged mice developed more severe corneal epitheliopathy. Previous reports using mouse models also have reported increased susceptibility to corneal barrier disruption in older animals. ${ }^{55,56}$ To our knowledge, the effect of desiccating stress rechallenge in DED (ie, > one period of exposure to a dry environment) has not been studied in aging. Based on the heightened disease response detected after rechallenge, and on our previous work studying immune memory in DED, ${ }^{33,35}$ we hypothesized that memory lymphocytes were driving the disproportionately greater clinical disease observed in aged animals relative to young animals.

Memory Th17 cells are key mediators of DED chronicity, and that this population drives the severe corneal epithelial disease observed after desiccating stress rechallenge. ${ }^{33,35}$ Notably, a similar role for memory Th17 cells has been reported using the experimental autoimmune encephalomyelitis model, in which memory Th17 cells showed rapid expansion in response to rechallenge and migrated in high frequencies to the central nervous system, resulting in accelerated onset and increased disease severity. ${ }^{9}$ However, the contribution of memory Th17 cells to age-related DED has not been investigated previously. Our data show an amplified effector Th17 response in aged mice after DED rechallenge relative to young mice, associated with higher frequencies of memory Th17 cells observed before rechallenge. To examine the contribution of memory Th17 cells to age-related DED, mice were treated systemically with anti-IL-15 mAb. IL-15 is recognized as a memorymaintaining cytokine, and targeting IL-15 has been shown to be an effective strategy for depleting immunopathogenic memory Th17 cells. ${ }^{35,57,58}$ Our data show that anti-IL-15 mAb successfully depleted the amplified memory Th17 pool observed in aged mice. Moreover, upon re-exposure to a low-humidity environment, anti-IL-15 mAb-treated aged mice showed reduced clinical disease with decreased effector Th17 cell infiltration. Collectively, these data suggest that an expanded pool of memory Th17 cells predispose toward severe exacerbations of DED in aged mice.

This study used anti-IL-15 mAb to deplete CD4 ${ }^{+}$ memory Th17 cells. It is important to note that IL-15 signaling also has been implicated in the activation and survival of $\mathrm{CD}^{+}$memory T cells. ${ }^{59,60}$ However, it is $\mathrm{CD} 4^{+}$ $\mathrm{T}$ cells, rather than $\mathrm{CD}^{+}$, that are recognized as the principal effector cells in DED. ${ }^{18,22,61}$ Studies have shown that adoptive transfer of $\mathrm{CD}^{+}{ }^{+} \mathrm{T}$ cells derived from mice exposed to desiccating stress transfers the disease phenotype to T-cell-deficient recipients. Indeed, the transferred $\mathrm{CD}^{+}$ $\mathrm{T}$ cells have been shown to home specifically to the cornea, conjunctiva, and draining lymph nodes, where they induce disease. ${ }^{2,25,62}$ Moreover, inhibition of the generation of ocular-specific autoreactive $\mathrm{CD} 4^{+} \mathrm{T}$ cells has been shown to abrogate this phenomenon. ${ }^{20}$

Because of the increased prevalence of DED in the elderly, as the older population expands, so too will the burden of DED-related morbidity. ${ }^{14}$ Accordingly, there is an unmet clinical need for treatments of age-associated ocular surface disease. As in the case of other human 
autoimmune disorders for which increased age is a risk factor (such as psoriasis ${ }^{63}$ and rheumatoid arthritis $^{64}$ ), modulating Th17-mediated immunity has emerged as a potential therapeutic strategy. ${ }^{17}$ These diseases are characterized by a chronic waxing-waning disease course, in which memory Th17 cells represent a constant threat, responding to putative self-antigens by triggering a rapid recall inflammatory response., ${ }^{6,}$ The current study elucidates differences in clinical disease severity and Th17 immunity between young and aged mice. Specifically, our data show that aged mice show a more severe and rapid onset of corneal epitheliopathy after repeated exposure to desiccating stress than young mice. Moreover, these results indicate that treatment with anti-IL-15 mAb depletes the memory Th17 population and abrogates the increased disease severity observed in aged mice. In doing so, this study provides new insights into the contribution of the long-lived memory Th17 cell population to age-related ocular surface autoimmunity. Further studies in mouse models may help us to elucidate age-related changes to the generation, maintenance, and function of this important subset of Th17 cells.

\section{Author Contributions}

W.F. conceived and designed the study, collected and analyzed the data, and wrote the manuscript; S.K.M. and Y.C. conceived and designed the study, collected and analyzed the data, and revised the manuscript; Y.T. and T.N. collected and analyzed data, and revised the manuscript; and S.K.C. and R.D. conceived and designed the study, analyzed the data, and revised the manuscript; all authors read and approved the final manuscript.

\section{Supplemental Data}

Supplemental material for this article can be found at http://doi.org/10.1016/j.ajpath.2020.03.016.

\section{References}

1. Thompson WW, Shay DK, Weintraub E, Brammer L, Cox N, Anderson LJ, Fukuda K: Mortality associated with influenza and respiratory syncytial virus in the United States. JAMA 2003, 289: 179-186

2. Guichelaar T, Hoeboer J, Widjojoatmodjo MN, Reemers SSN, van Els CACM, Otten R, van Remmerden Y, Boes J, Luytjes W: Impaired immune response to vaccination against infection with human respiratory syncytial virus at advanced age. J Virol 2014, 88: 9744-9750

3. Goronzy JJ, Weyand CM: Immune aging and autoimmunity. Cell Mol Life Sci 2012, 69:1615-1623

4. Weng N-P: Aging of the immune system: how much can the adaptive immune system adapt? Immunity 2006, 24:495-499

5. Devarajan P, Chen Z: Autoimmune effector memory T cells: the bad and the good. Immunol Res 2013, 57:12-22

6. McGeachy MJ: Th17 memory cells: live long and proliferate. J Leukoc Biol 2013, 94:921-926
7. Burkett PR, Meyer zu Horste G, Kuchroo VK: Pouring fuel on the fire: Th17 cells, the environment, and autoimmunity. J Clin Invest $2015,125: 2211-2219$

8. Kryczek I, Zhao E, Liu Y, Wang Y, Vatan L, Szeliga W, Moyer J, Klimczak A, Lange A, Zou W: Human TH17 cells are long-lived effector memory cells. Sci Transl Med 2011, 3:104ra100

9. Haines CJ, Chen Y, Blumenschein WM, Jain R, Chang C, JoyceShaikh B, Porth K, Boniface K, Mattson J, Basham B, Anderton SM, McClanahan TK, Sadekova S, Cua DJ, McGeachy MJ: Autoimmune memory $\mathrm{T}$ helper 17 cell function and expansion are dependent on interleukin-23. Cell Rep 2013, 3:1378-1388

10. Miljanović B, Dana R, Sullivan DA, Schaumberg DA: Impact of dry eye syndrome on vision-related quality of life. Am J Ophthalmol 2007, 143:409-415

11. Crnej A, Kheirkhah A, Ren A, Mullins A, Lavric A, Suri K, Hamrah P, Dana R: Patients' perspectives on their dry eye disease. Ocul Surf 2016, 14:440-446

12. Bradley JL, Özer Stillman I, Pivneva I, Guerin A, Evans AM, Dana R: Dry eye disease ranking among common reasons for seeking eye care in a large US claims database. Clin Ophthalmol 2019, 13:225-232

13. Craig JP, Nelson JD, Azar DT, Belmonte C, Bron AJ, Chauhan SK, de Paiva CS, Gomes JAP, Hammitt KM, Jones L, Nichols JJ, Nichols KK, Novack GD, Stapleton FJ, Willcox MDP, Wolffsohn JS, Sullivan DA: TFOS DEWS II report executive summary. Ocul Surf 2017, 15:802-812

14. Dana R, Bradley JL, Guerin A, Pivneva I, Stillman IO, Evans AM, Schaumberg DA: Estimated prevalence and incidence of dry eye disease based on coding analysis of a large, all-age United States health care system. Am J Ophthalmol 2019, 202:47-54

15. Guzmán M, Keitelman I, Sabbione F, Trevani AS, Giordano MN, Galletti JG: Desiccating stress-induced disruption of ocular surface immune tolerance drives dry eye disease. Clin Exp Immunol 2016, $184: 248-256$

16. Guzmán M, Keitelman I, Sabbione F, Trevani AS, Giordano MN Galletti JG: Mucosal tolerance disruption favors disease progression in an extraorbital lacrimal gland excision model of murine dry eye. Exp Eye Res 2016, 151:19-22

17. Stevenson W, Chauhan SK, Dana R: Dry eye disease. Arch Ophthalmol 2012, 130:90

18. Barabino S, Chen Y, Chauhan S, Dana R: Ocular surface immunity: homeostatic mechanisms and their disruption in dry eye disease. Prog Retin Eye Res 2012, 31:271-285

19. Foulsham W, Coco G, Amouzegar A, Chauhan SK, Dana R: When clarity is crucial: regulating ocular surface immunity. Trends Immunol 2018, 39:288-301

20. Schaumburg CS, Siemasko KF, De Paiva CS, Wheeler LA, Niederkorn JY, Pflugfelder SC, Stern ME: Ocular surface APCs are necessary for autoreactive $\mathrm{T}$ cell-mediated experimental autoimmune lacrimal keratoconjunctivitis. J Immunol 2011, 187:3653-3662

21. Pflugfelder SC, Stern M, Zhang S, Shojaei A: LFA-1/ICAM-1 interaction as a therapeutic target in dry eye disease. J Ocul Pharmacol Ther 2017, 33:5-12

22. Stern ME, Schaumburg CS, Pflugfelder SC: Dry eye as a mucosal autoimmune disease. Int Rev Immunol 2013, 32:19-41

23. Bron AJ, de Paiva CS, Chauhan SK, Bonini S, Gabison EE, Jain S, Knop E, Markoulli M, Ogawa Y, Perez V, Uchino Y, Yokoi N, Zoukhri D, Sullivan DA: TFOS DEWS II pathophysiology report. Ocul Surf 2017, 15:438-510

24. Yamaguchi T: Inflammatory response in dry eye. Invest Ophthalmol Vis Sci 2018, 59:DES192

25. Chauhan SK, El Annan J, Ecoiffier T, Goyal S, Zhang Q, Saban DR, Dana R: Autoimmunity in dry eye is due to resistance of Th17 to Treg suppression. J Immunol 2009, 182:1247-1252

26. Chauhan SK, Dana R: Role of Th17 cells in the immunopathogenesis of dry eye disease. Mucosal Immunol 2009, 2:375-376

27. De Paiva CS, Chotikavanich S, Pangelinan SB, Pitcher JD, Fang B, Zheng X, Ma P, Farley WJ, Siemasko KF, 
Niederkorn JY, Stern ME, Li D-Q, Pflugfelder SC: IL-17 disrupts corneal barrier following desiccating stress. Mucosal Immunol 2009, 2:243-253

28. Amadi-Obi A, Yu C-R, Liu X, Mahdi RM, Clarke GL, Nussenblatt RB, Gery I, Lee YS, Egwuagu CE: TH17 cells contribute to uveitis and scleritis and are expanded by IL-2 and inhibited by IL27/STAT1. Nat Med 2007, 13:711-718

29. Hirota K, Yoshitomi H, Hashimoto M, Maeda S, Teradaira S, Sugimoto N, Yamaguchi T, Nomura T, Ito H, Nakamura T, Sakaguchi N, Sakaguchi S: Preferential recruitment of CCR6expressing Th17 cells to inflamed joints via CCL20 in rheumatoid arthritis and its animal model. J Exp Med 2007, 204: $2803-2812$

30. Abraham C, Cho J: Interleukin-23/Th17 pathways and inflammatory bowel disease. Inflamm Bowel Dis 2009, 15:1090-1100

31. Kebir H, Kreymborg K, Ifergan I, Dodelet-Devillers A, Cayrol R, Bernard M, Giuliani F, Arbour N, Becher B, Prat A: Human TH17 lymphocytes promote blood-brain barrier disruption and central nervous system inflammation. Nat Med 2007, 13: $1173-1175$

32. Stern ME, Schaumburg CS, Dana R, Calonge M, Niederkorn JY, Pflugfelder SC: Autoimmunity at the ocular surface: pathogenesis and regulation. Mucosal Immunol 2010, 3:425-442

33. Chen Y, Chauhan SK, Soo Lee H, Saban DR, Dana R: Chronic dry eye disease is principally mediated by effector memory Th17 cells. Mucosal Immunol 2014, 7:38-45

34. Tan X, Chen Y, Foulsham W, Amouzegar A, Inomata T, Liu Y, Chauhan SK, Dana R: The immunoregulatory role of corneal epithelium-derived thrombospondin-1 in dry eye disease. Ocul Surf 2018, 16:470-477

35. Chen Y, Chauhan SK, Tan X, Dana R: Interleukin-7 and -15 maintain pathogenic memory Th17 cells in autoimmunity. J Autoimmun 2017, 77:96-103

36. Barabino S, Shen L, Chen L, Rashid S, Rolando M, Dana MR: The controlled-environment chamber: a new mouse model of dry eye. Invest Ophthalmol Vis Sci 2005, 46:2766

37. Lenz DC, Kurz SK, Lemmens E, Schoenberger SP, Sprent J, Oldstone MBA, Homann D: IL-7 regulates basal homeostatic proliferation of antiviral CD4+T cell memory. Proc Natl Acad Sci U S A 2004, 101:9357-9362

38. Purton JF, Tan JT, Rubinstein MP, Kim DM, Sprent J, Surh CD: Antiviral CD4+ memory T cells are IL-15 dependent. J Exp Med 2007, 204:951-961

39. Surh CD, Sprent J: Homeostasis of naive and memory T cells. Immunity 2008, 29:848-862

40. Shukla S, Mittal SK, Foulsham W, Elbasiony E, Singhania D, Sahu SK, Chauhan SK: Therapeutic efficacy of different routes of mesenchymal stem cell administration in corneal injury. Ocul Surf 2019, 17:729-736. ARVO Annua

41. Mittal SK, Foulsham W, Shukla S, Elbasiony E, Omoto M, Chauhan SK: Mesenchymal stromal cells modulate corneal alloimmunity via secretion of hepatocyte growth factor. Stem Cells Transl Med 2019, 8:1030-1040

42. Dohlman TH, Chauhan SK, Kodati S, Hua J, Chen Y, Omoto M, Sadrai Z, Dana R: The CCR6/CCL20 axis mediates Th17 cell migration to the ocular surface in dry eye disease. Invest Ophthalmol Vis Sci 2013, 54:4081-4091

43. Kodati S, Chauhan SK, Chen Y, Dohlman TH, Karimian P, Saban D, Dana R: CCR7 is critical for the induction and maintenance of Th17 immunity in dry eye disease. Invest Ophthalmol Vis Sci 2014, 55: $5871-5877$

44. Fulop T, Larbi A, Dupuis G, Le Page A, Frost EH, Cohen AA, Witkowski JM, Franceschi C: Immunosenescence and inflamm-aging as two sides of the same coin: friends or foes? Front Immunol 2017, $8: 1960$

45. Fulop T, Dupuis G, Baehl S, Le Page A, Bourgade K, Frost E, Witkowski JM, Pawelec G, Larbi A, Cunnane S: From inflamm-aging to immune-paralysis: a slippery slope during aging for immuneadaptation. Biogerontology 2016, 17:147-157

46. Franceschi C, Bonafè M, Valensin S, Olivieri F, De Luca M, Ottaviani E, De Benedictis G: Inflamm-aging. An evolutionary perspective on immunosenescence. Ann N Y Acad Sci 2000, 908: 244-254

47. Rea IM, Gibson DS, McGilligan V, McNerlan SE, Alexander HD, Ross OA: Age and age-related diseases: role of inflammation triggers and cytokines. Front Immunol 2018, 9:586

48. Micera A, Di Zazzo A, Esposito G, Longo R, Foulsham W, Sacco R, Sgrulletta R, Bonini S: Age-related changes to human tear composition. Invest Ophthalmol Vis Sci 2018, 59:2024

49. Wei A, Hong J, Sun X, Xu J: Evaluation of age-related changes in human palpebral conjunctiva and meibomian glands by in vivo confocal microscopy. Cornea 2011, 30:1007-1012

50. Furukawa RE, Polse KA: Changes in tear flow accompanying aging. Am J Optom Physiol Opt 1978, 55:69-74

51. Nasu M, Matsubara O, Yamamoto H: Post-mortem prevalence of lymphocytic infiltration of the lacrymal gland: a comparative study in autoimmune and non-autoimmune diseases. J Pathol 1984, 143: $11-15$

52. Obata H, Yamamoto S, Horiuchi H, Machinami R: Histopathologic study of human lacrimal gland. Statistical analysis with special reference to aging. Ophthalmology 1995, 102:678-686

53. Liu R, Gao C, Chen H, Li Y, Jin Y, Qi H: Analysis of Th17associated cytokines and clinical correlations in patients with dry eye disease. PLoS One 2017, 12:e0173301

54. Barbosa FL, Xiao Y, Bian F, Coursey TG, Ko BY, Clevers H, de Paiva CS, Pflugfelder SC: Goblet cells contribute to ocular surface immune tolerance-implications for dry eye disease. Int $\mathrm{J}$ Mol Sci 2017, 18

55. McClellan AJ, Volpe EA, Zhang X, Darlington GJ, Li D-Q, Pflugfelder SC, de Paiva CS: Ocular surface disease and dacryoadenitis in aging C57BL/6 mice. Am J Pathol 2014, 184: 631-643

56. Coursey TG, Bian F, Zaheer M, Pflugfelder SC, Volpe EA, de Paiva CS: Age-related spontaneous lacrimal keratoconjunctivitis is accompanied by dysfunctional T regulatory cells. Mucosal Immunol 2017, 10:743-756

57. Berard M, Brandt K, Bulfone-Paus S, Tough DF: IL-15 promotes the survival of naive and memory phenotype CD8+ T cells. J Immunol 2003, 170:5018-5026

58. Stonier SW, Ma LJ, Castillo EF, Schluns KS: Dendritic cells drive memory CD8 T-cell homeostasis via IL-15 transpresentation. Blood 2008, 112:4546-4554

59. Weng N-P, Liu K, Catalfamo M, Li Y, Henkart PA: IL-15 is a growth factor and an activator of CD8 memory T cells. Ann N Y Acad Sci 2002, 975:46-56

60. Sato N, Patel HJ, Waldmann TA, Tagaya Y: The IL-15/IL-15Ralpha on cell surfaces enables sustained IL-15 activity and contributes to the long survival of CD8 memory T cells. Proc Natl Acad Sci U S A 2007, 104:588-593

61. El Annan J, Chauhan SK, Ecoiffier T, Zhang Q, Saban DR, Dana R: Characterization of effector T cells in dry eye disease. Invest Ophthalmol Vis Sci 2009, 50:3802-3807

62. Niederkorn JY, Stern ME, Pflugfelder SC, De Paiva CS, Corrales RM, Gao J, Siemasko K: Desiccating stress induces T cellmediated Sjögren's syndrome-like lacrimal keratoconjunctivitis. J Immunol 2006, 176:3950-3957

63. Fitch E, Harper E, Skorcheva I, Kurtz SE, Blauvelt A: Pathophysiology of psoriasis: recent advances on IL-23 and Th17 cytokines. Curr Rheumatol Rep 2007, 9:461-467

64. Leipe J, Grunke M, Dechant C, Reindl C, Kerzendorf U, SchulzeKoops H, Skapenko A: Role of Th17 cells in human autoimmune arthritis. Arthritis Rheum 2010, 62:2876-2885

65. Clark RA: Resident memory T cells in human health and disease. Sci Transl Med 2015, 7:269rv1 